\title{
DIOSAS Y HECHICERAS: LA VISIÓN DE LA MAGIA Y LA MUJER EN LA ANTIGÜEDAD GRECO-ROMANA ${ }^{1}$
}

\author{
José Antonio Aranda García
}

\begin{abstract}
Diosas y hechiceras: la visión de la magia y la mujer en la antigüedad greco-romana
Resumen: Aunque la magia es una realidad en el mundo antiguo, su práctica no es aprobada por la ciudad. La condena a lo relativo a la magia destaca por su relación con la mujer; las hechiceras son mujeres y las deidades que protegen la magia, diosas. Esta relación se justifica en el temor al poder que puede desarrollar la mujer, por parte del patriarcado.

Palabras clave: Magia, antigüedad, hechiceras, diosas.
\end{abstract}

Goddesses and Sorceresses: The Visión of Magic and Women in Graeco-Roman Antiquity

Abstract: Although magic is a reality in the ancient world, magic practice is not approved in the city. Concerns about magic are directly related to its relation to women. Sorceresses are women and deities that protect the magic are goddesses. This relation is justified by the patriarchal fear of the power that women can develop.

Keywords: Magic, antiquity, sorceresses, goddesses.

\section{Introducción}

Exponemos en este artículo la existencia de tres realidades paralelas que resultan indicativo de la relación de la mujer y la magia en el mundo grecorromano. En primer lugar la existencia de una serie de diosas que se relacionan con la magia y que sirven de vía hacia la práctica de esta. De otra, la aparición de practicantes de magia en la literatura griega y romana, muestra de la existencia en estas prácticas en el imaginario de los escritores y de la población de la antigüedad clásica; si bien aparejadamente aparece el problema derivado del desconocimiento de los límites de la realidad que muestra la literatura. Finalmente, la existencia real de prácticas mágicas que reflejan los restos arqueológicos y que sirven de muestra de aquellas prácticas pero con matices sobre la concepción literaria de las mismas.

\footnotetext{
${ }^{1}$ Fecha de recepción: 11/10/2016.

Fecha de aceptación: 21/12/2016.

2 Doctorando en el Programa de Doctorado en Patrimonio, Universidad de Córdoba; $\square$ jaag0004@ujaen.es.
} 
Si bien existen multitud de formas de definir a las personas relacionadas con la práctica mágica en el periodo grecorromano, particularmente a las mujeres, dependiendo de la especialidad mágica de cada una (Dickie 2005:49); las denominaremos aquí hechiceras, forma en la que las fuentes las denominan genéricamente (Dickie 2005: 15).

\section{La concepción de la magia en el mundo grecorromano}

El estudio de la magia parte con la dificultad añadida de definir el campo objeto del mismo. Las definiciones han sido numerosas; en general se la considera un conjunto de creencias y ritos de carácter sobrenatural realizados por la población con el objeto de interactuar con el medio que le rodea para manipularlo y conseguir un beneficio propio. A diferencia de la religión, que se encuentra estructurada y trata de calmar las inquietudes de la población con la explicación de aquello desconocido, la magia opta por interactuar con el objeto del problema en un intento, no solo de explicar, sino de participar de la naturaleza del mismo. Existen diferentes explicaciones sobre esta: para Malinowski se trata de una observación de la naturaleza desde un estado subjetivo, más emocional que lógico; para Levi- Strauss, se trata de un método con el que dar explicación a aquellos elementos que escapan a lo común, para mantener la lógica de la estructura (Apud 2011: 12-13); para Piobb, es el medio del que el hombre se sirve para disponer de las energías del universo en cualquiera que sea su forma; para manipular la energía de la naturaleza en conjunción con la del hombre (Vázquez 1989: 171-196).

Sobre el origen de la magia, algunos consideran que se trata de un estadio previo a la aparición de la filosofía y la ciencia, que planteaba una explicación del mundo mediante conceptos arraigados en la tradición y la superstición popular (Flint y otros 1999: 84). Otros, como Wagner, que se trata de una práctica legada de otras chamánicas previas; entendido el chamanismo como conjunto de prácticas de carácter mágicoreligioso no reglado por una institución.

2.1. El concepto de magia en la antigüedad grecorromana 
En cualquier caso, la práctica mágica en la antigüedad posiblemente fuese algo común. La gente de a pie realizaba prácticas que consideraba mágicas, como queda mostrado con la existencia de restos arqueológicos tales como las tablillas de defixio, comunes por todo el Imperio, así como amuletos y mosaicos que pretenden la protección contra estas prácticas y compendios de hechizos. La magia era pues concebida como algo real y tangible entre los antiguos griegos y romanos.

A la par se concibe esta de una forma dual. Aunque en la mayor parte de los casos se señala como una práctica perniciosa por exceder los límites de la religión indisociable de la propia ciudad, en ocasiones las prácticas mágicas se conciben como elementos propios de rituales de la ciudad o incluso mecanismos usuales en prácticas cotidianas como la medicina (Dickie 2005: 23-24).

Los griegos consideran las prácticas mágicas como propias del otro, del extranjero, y usualmente como provenientes de oriente, de Egipto o de tierras bárbaras, del mismo modo Roma considera a los sabinos y pelasgos como los practicantes de las artes mágicas (Luck 2006: 36-37). También existen prácticas asociadas a la propia comunidad; en tal caso se consideran propias de habitantes de zonas agro-ganaderas, que habitan en las montañas apartados de la ciudad. Incluso cuando se trata de prácticas de la ciudad, dentro de esta se asocian a esclavos y a mujeres; se trata en todo caso, del "otro", pues no son prácticas adecuadas a la condición de ciudadano (Martin 2012: 14-16). En todo caso, la magia tiene dos vertientes que cabe distinguir: la magia que pretende un beneficio para la comunidad, que era lícita y estaba aceptada, siendo ejercida por diferentes sacerdocios de la ciudad; y la magia con fines egoístas o perniciosos, que era repudiada por la comunidad e incluso condenada y que se asimilaba, como se ha dicho, al otro (Caro 1996: 37-39), al que quedaba fuera de los limites reglados por la comunidad (Teja 2014: 48-49).

Por otro lado, no podemos dejar de considerar como realidad de la magia en la antigüedad grecorromana, la concepción ideológica de estas prácticas y su plasmación en la literatura y otras obras de la época. A la misma aluden multitud de autores clásicos, tanto literatos como historiadores, desde Ovido a Flavio Josefo o Plinio. El interés de 
estos autores en el asunto nos conduce irremediablemente a varias reflexiones: primero que el interés pudo surgir por la observación de una práctica real, que se estuviera realizando y fuera de público conocimiento; y segundo, que el propio interés de estos y el plasmado por escrito en sus obras, contribuyó a crear una imagen colectiva de aquello que describían, pudiendo influir en ciertos casos en la realidad de su tiempo.

\subsection{Visión desde la polis y la civitas}

La ciudad se mostró siempre contra estas prácticas. En el mundo griego, ya Platón se interesa por su existencia y hace mención a la existencia de una magia cotidiana; aunque nunca la define, sí que la relaciona con la medicina y con la mantica. Los que la practican son, para el filósofo, personajes que niegan la existencia de los dioses y manipulan las almas, y por ello peligrosos para la ciudad. Los practicantes de magia han de ser aprisionados, privados de todo contacto con el exterior y de sepultura a su muerte. Para Platón la magia puede provocar daños sociales y psicológicos, no teniendo cabida en la ciudad. Sus referencias parecen hacer eco de una práctica que sin duda existía en la ciudad y se encontraba muy extendida (Martin 2012: 96-98).

Ante la inmoralidad que representaba la misma, la existencia real y su extensión, tanto griegos como romanos plantearon diversas medidas para impedir su existencia, muestra de la misma. La legislación Griega no es muy conocida al respecto, aunque parece que fue prohibitiva como demuestran las acusaciones por envenenamiento mediante el uso pociones mágicas. Por una de estas acusaciones se condenará a muerte a Theoris de Lemnos en el siglo IV a.C., una mujer que fue fácilmente acusada de brujería y condenada a ser lapidada. La brujería fue usada como forma de expiación de los problemas que pudiera presentar la ciudad, recayendo la acusación de brujería en las mujeres, que pagaban con su vida la superstición popular (Martin 2012: 103-104).

En Roma desde muy pronto estas prácticas son legisladas como encontramos reflejado en la Ley de las Doce Tablas, donde se penaliza a quien pretenda hacer uso de sortilegios o pronuncie maldiciones (Plinio, HN, XXVIII, 17). De hecho, acusadas de 
atentar contra el estado por el envenamiento de ciudadanos mediante el empleo de venenos, serán ejecutadas un grupo de mujeres en Roma en 331 a.C. (Muro 2000: 233). Posteriormente también se legislará contra otras prácticas hechiceras: se prohibirá el empleo de drogas, considerado envenamiento y castigado con severas penas según la Lex Cornelia de Sicariis et Veneficiis de 81 a.C. (Martin 2012: 105-107). Así mismo, Agripa llama a odiar y a castigar a los magos porque introducen elementos no aceptados en la religión, con el peligro que ello conlleva para la ciudad, y expulsa a diversos en el año 33 a.C. ante el temor a las prácticas relacionadas con la magia, Augusto mandará quemar los libros de profecías en 31 a.C. y expulsa al pitagórico Anaxilao de Larissa de Roma y de Italia en 28 a.C. (Ogden 2009: 280-281).

Ya en el Imperio, Livio Druso condena ante Tiberio las prácticas mágicas decretando el Senado que los astrólogos sean expulsados de Italia. Nerón condenará la adivinación con la muerte y expulsará a los astrólogos de Italia en 52 d.C. Así mismo, Pablo ordena quemar los libros de magia a los conversos Efesos, y Vitelio condena la práctica mágica de los caldeos con la muerte en la segunda mitad del siglo I d.C. La prohibición alcanza tal grado que se condenan a la hoguera a algunas mujeres ya en el siglo I d.C. ante las acusaciones de brujería. Será finalmente Constantino quien prohíba a hechiceras, astrólogos y otros similares en todo el Imperio (Ogden 2009: 282-285).

\section{Las deidades de la magia: diosas}

La práctica mágica se desarrolló en buena medida gracias al permisivo marco politeísta en el que las diferentes creencias tuvieron una relativa aceptación; aunque no se diese una apertura hacia todo tipo de prácticas. El fundamento de la creencia mágica descansó siempre sobre la relación con algún tipo de divinidad clásica, o bien en relación con una divinidad bárbara o con los denominados demons ${ }^{3}$. Serán, por tanto, en buena medida, divinidades de la tradición griega que en muchos casos hunden sus raíces en un

\footnotetext{
${ }^{3}$ Se trata de unas criaturas sobrenaturales que hacían las veces de asistentes de los practicantes mágicos. Junto a estos encontramos a los difuntos que toman parte de las prácticas mágicas, o bien son víctimas de ellas.
} 
pasado remoto, quizá previo a la sociedad agrícola, en el que la mujer tendría una relativa menor subyugación que en el patriarcado grecorromano, así como en la oscura tradición religiosa oriental.

\subsection{Hécate}

Entre las diferentes divinidades protectoras de magos y hechiceras y receptoras de sus peticiones destaca Hécate, una diosa de gran antigüedad, que aparece ya en la Teogonía de Hesíodo (Th. 410) con algunos rasgos de las divinidades indígenas. Hija de Perses y Asteria, nieta de Urano, perteneciente a la generación de los Ríos, las Oceánides, Helios o Selene. Se trata de una deidad relacionada con los Titanes, más antigua que los propios dioses (Villalba 2015: 3). Se asocia a un papel marginal, a la par que sus coetáneos titanes son desplazados del Olimpo por los nuevos dioses (Martin 2012: 28); se observa aquí el reflejo de la Historia, con la supremacía de los dioses de la ciudad y la aristocracia patrilineal, sobre las deidades antiguas más cercanas al culto de la naturaleza, que quedan relegadas a un plano secundario. Otra versión de su origen la ofrece Apolodoro (Bibliotheca, 37) en su explicación sobre la descendencia de los titanes; muestra aquí diversas concesiones hechas por Zeus a la diosa: frente a los titanes caídos, Hécate conserva el epíteto de Gran Diosa y es venerada como otras del panteón griego y sin especial relación con la práctica mágica, al menos al principio; aún en el siglo $\mathrm{V}$ a.C. no se la considera como diosa de la magia. La encontramos como diosa de las encrucijadas; concepción por la que se generarán representaciones tricéfalas de la diosa llamadas Hekateion, que se situarán en el centro de los cruces para señalar las tres direcciones; los cruces tendrán un papel destacado en la magia, ya que en ellos se realizan algunas prácticas de este tipo (Villalba 2015: 9).

A la vez es hija de dos conceptos opuestos que la relacionan con la vida, las tinieblas y la luz y se la relaciona con tres elementos: la tierra, el mar y el cielo; así, en las invocaciones a la misma, se la relaciona con Helios, Selene y Eos (Mérida 2004: 17). Esta polivalencia es muestra de la creencia en el gran poder de la diosa, tal es este, que su nombre significa "aquella que extiende su poder en lo lejano". La multiplicidad de sus 
facetas hace que sus poderes sean asimilados con facilidad por otras diosas que pugnan con la aparente supremacía de esta deidad de mayor antigüedad; comparte caracteres con Perséfone en la relación con el mundo infernal, con Artemis en su relación con la tierra, y con Selene por su concepción celeste (Martin 2012: 29).

Ya desde finales del siglo $\mathrm{V}$, pero sobre todo con el final de la época griega clásica, los lazos de Hécate con los aspectos mágicos se hacen más relevantes (Dickie 2005:34); aparece en invocaciones en tablillas de defixio y en himnos de los textos mágicos donde se representa claramente la unificación de las concepciones de esta diosa y sus campos de acción, y sus relaciones con otras diosas (PGM IV: 2715 -2733).

Será venerada por igual por hombres y mujeres de toda clase, rango y oficio, incluso se considera que los dioses sienten profundo respeto por ella (Mérida 2004: 19). Tal respeto evoluciona convirtiéndose en temor y haciendo virar la imagen de la diosa hacia el patronazgo de la magia y de las hechiceras; aparece así por primer vez en Las mujeres Cólquidas de Sófocles como coronada por serpientes y asociada a los muertos que no descansan en paz; finalmente en la época helenística acaba por definirse y relacionarse con el mundo de ultratumba (Mérida 2004: 20). Aparece como una diosa anciana, relacionada con la fase oscura de la luna en contraposición a Artemis y Selene (la luna creciente y la llena). Se trata del arquetipo de mujer sabia en la que convergen las diferentes divinidades relacionadas al legar a la etapa de vejez. Es una diosa enlazada con el submundo, de donde procede su sabiduría; así en el segundo himno de Homero se describe como es Hécate la que consuela y aconseja a Deméter cuando Perséfone es raptada y llevada al inframundo (Hom him. II, 1).

\subsection{Otras deidades mágicas}

Otras deidades del panteón grecorromano ocupaban el imaginario como protectoras y participantes de rituales mágicos, siendo apeladas por los practicantes. Destaca Artemis a la que se suele asociar a Hécate (Dickie 2005: 97 y100), Perséfone y Selene (Luck 2006: 57), así como sus correlativas romanas. Se tratan en todos los casos 
de deidades relacionadas con el inframundo y con la luna, dos elementos de gran importancia en el ritual mágico.

Entre las divinidades extranjeras destacan las egipcias y las orientales. Especialmente importante fue el culto a Isis, la gran hechicera egipcia hacedora de hechizos y gran encantadora; aunque es invocada en Egipto desde muy antiguo, desde época helenística y especialmente con Roma, su culto se extiende por el Mediterráneo. Aparecen templos dedicados a sus misterios en todo el Imperio y es frecuente en tabillas de defixio. Entre las diosas orientales destaca Ereschigal, asimilada a Hécate en las tabillas (Martin 2012: 35).

Escasean las deidades masculinas. Destaca Hermes- Mercurio en su faceta ctónica, mencionado en tablillas (aunque relativamente tardías, ya de época helenística). Se trata de una asimilación posterior, posiblemente por la relación de Hermes- Mercurio con la transición hacia la muerte y su capacidad como portador de mensajes. No deja de tener importancia la relación de Mercurio con Hécate, pues la primera referencia que tenemos de este en relación lo mágico, procede de una tablilla órfica en la que son mencionados juntos (Martin 2012: 31). También es frecuente la aparición de este Hermes de tintes mágicos en relación con el dios egipcio Thot, revelador de las prácticas mágicas (Luck 2006: 57). Se trata por tanto de facetas, en cierto modo pervertidas de este dios, pues aparece en relación con elementos excluidos de la sociedad: mujeres y extranjeros (Esteban 2005: 78). Sin embargo, la relación de Hermes con las prácticas mágicas puede observarse también en época arcaica en la Odisea de Homero, donde Ulises se protege de los hechizos de la hechicera Circe con una poción que le ofrece Hermes (Hom. Od. X, 281-302). El dios aparece en este caso como antítesis de la hechicera; aunque conoce las prácticas usa su conocimiento de forma positiva en una suerte de magia blanca.

La diferencia entre unas y otro parecen claras a simple vista. Las diosas que se relacionan con la magia son divinidades oscuras, de la noche y relacionadas con el inframundo o con lo extranjero; en especial Hécate, la divinidad mágica por antonomasia y en la que acaban referenciando las otras, que además se presenta como una vieja. Por el 
contrario, el dios que puede llegar a relacionarse con la magia o bien lo hace influido por las diosas anteriores o bien con finalidades positivas (Fernández 2006: 104).

\section{Las hechiceras en la literatura grecorromana}

La magia es impartida por el magus y más aún por la hechicera, que con sus poderes llevan a cabo prodigios propios, en ocasiones, de los propios dioses. Aparecen estos en las fuentes con cualidades de hechiceras-tipo, poderes divinos y capacidades mágicas inabarcables que plantean la imposibilidad de su existencia real. (Dickie 2005: 12)

Las hechiceras aparecen citadas en la mayor parte de los casos por su nombre propio, o bien con algún sustantivo que las identifica. La importancia de éstas reside, para nosotros, en la imagen que crean los relatos sobre ellas y el arquetipo de hechicera, reflejo en última instancia de la consideración social sobre los practicantes de magia, reales o no.

La literatura griega tratará ampliamente la temática mágica y servirá como fuente de inspiración del imaginario romano; la concepción griega de la magia se remonta a épocas oscuras con referencias en los poemas homéricos con figuras que podemos considerar como hechiceras. Se trata aquí de dilucidar la visión que los autores hacen llegar al pueblo a través de sus obras, crean ellos o no en aquello que describen, sea o no reflejo de su realidad cotidiana.

\subsection{Herencia de la antigua Grecia}

Circe es la primera hechicera de la que tenemos conocimiento en la literatura griega. Aparece por primera vez en la Odisea (Hom. Od. X). Habitaba en un palacio en el bosque, rodeado por fieras que había hechizado con brebajes mágicos; atrajo a los compañeros de Ulises con cánticos, y con pociones y su bastón mágico les transformó en cerdos; Ulises escapa del embrujo con un antídoto que le entrega Hermes; incapaz de vencer al héroe, Circe les libera tras obligarle a yacer con ella; finalmente, cuando deciden 
partir, les explica cómo conseguir ayuda del adivino Tiresias que se encuentra en el Hades (Hom. Od. X, 135-569). Como vemos, ya en la obra de Homero podemos encontrar los elementos que identificarán a las hechiceras: el uso de pócimas, la varita mágica y la palabra trasformadora con la que la acompaña ${ }^{4}$; elemento que de nuevo vuelve a remitir Hermes, al tratarse de un atributo propio de este (Galindo 2013: 15).

La hechicera se muestra como perteneciente al mundo de lo natural, enfrentado al urbano de la polis; representa lo salvaje frente a lo cívico griego: habita en el bosque, del que hace uso tanto por las hierbas como por el propio bastón (una rama arbórea); y se rodea de fieras, a las que amansa con sus artes mágicas. Una segunda cualidad es el empleo de brebajes con las que controla a las bestias y hechiza a los hombres (un poder que atenta contra el sistema establecido en el que la mujer ha de obedecer y no controlar y que usa de una forma traicionera propia tan solo de mujeres, carente del actuar heroico de los hombres). Además seduce con su cantar y obliga a Ulises a yacer con ella; muestra otro de los caracteres de la mujer: su libido y lujuria incontenibles. Finalmente, tiene conocimientos nigrománticos que relacionan magia e inframundo, como en el caso de Hécate. Se contrapone en todo modo a las virtudes propias del héroe.

La figura de Medea da a conocer algunas otras cualidades atribuidas a las hechiceras en la literatura griega. Su leyenda parece remontarse a la Época Oscura, siendo recogida por Eurípides y en Los Argonautas de Apolonio de Rodas, en el siglo III a.C. En la obra Medea, del primero, ante el temor de perder a su amado, la hechicera no dudará en hechizar unas joyas que envía a la pretendiente de este y que causan la muerte a esta mujer y a su padre (Eur. Med. 784); muestra así la falta de escrúpulos de la hechicera, que no duda en nada por sus pretensiones. En Los Argonautas ${ }^{5}$ es una joven sacerdotisa de Hécate, de quien obtiene poderes derivados de conjuros y pociones con los que puede detener los ríos o desviar a los astros y sale en las noches en busca de cadáveres para elaborar sus filtros (Lillo 2013: 157). La relación con la diosa es directa, siendo la fuente de sus poderes, que se relacionan también con el mundo natural, pues es capaz de

\footnotetext{
${ }^{4}$ Se hace mención a un bastón en lugar de una varita, que sería la forma evolucionada de este.

${ }^{5}$ La obra de Eurípides se centra en el final de las aventuras de Jasón y Medea, en Los Argonautas se completan las aventuras de Jasón, sus compañeros y Medea.
} 
controlar los elementos. Como en el caso anterior, se muestra la clara relación de la hechicera con el mundo de los muertos.

Como en el caso de Circe, un héroe desembarca en las tierras de la hechicera, Jasón, del que queda prendada y al acompaña y ayuda en sus aventuras. Le proporciona un ungüento llamado "prometeico" con el que si "tras conciliar en sacrificios nocturnos a la unigénita Daira"6 se unge el cuerpo se hace indestructible (A.R. III, 845- 857). Su conocimiento de las hierbas y otros elementos con los que realizar pociones mágicas queda pues patente.

En ayuda del héroe, no duda en oponerse a los deseos de su propio padre, abandonar su casa y permitir la muerte de su propio hermano. De nuevo se nos recalca una de las cualidades de las hechiceras propia de las mujeres, que la ejerce gracias a su poder: cegada por su lujuria, no duda en traicionar a su propia familia, permitiendo la muerte de su hermano, terribles crímenes en la sociedad griega con gran peso del padre y del heredero varón. (Esteban 2005: 69) La hechicera es conocedora de las más peligrosas artes y un claro peligro para la sociedad.

Simeta es una hechicera en la que se centra el Idilio II de Teócrito, que presenta las pasiones de ésta y una completa descripción de sus prácticas hechiceras; se trata de un personaje conocido por medio de esta obra poética, que sin embargo algunos autores creen que puede reflejar un personaje real (Mérida 2004: 50-51). Se trata una hechicera asentada en Alejandría, lugar donde confluyen las prácticas mágicas griegas con las egipcias ancestrales. En la obra, la propia hechicera narra a la Luna y a Hécate su desengaño amoroso, invocándolas para ponerle remedio mediante la magia; guiada por las pasiones irrefrenables propias de las mujeres queda prendada del más bello atleta de las fiestas de Artemis (otra de las diosas recurrentes), con el que yace durante días; cuando este deja de visitarla y llega a oídos de Simeta su amor por otra, prepara un encantamiento para atraerle o llevarlo a la muerte (Theoc. Idil. II). La hechicera muestra aquí de nuevo el deseo sexual descontrolado de la mujer, además de su actitud vengativa y posesiva.

\footnotetext{
${ }^{6}$ Otra forma de mención a Hécate, Hes. Th. 408-452.
} 
Resulta de interés el análisis pormenorizado de la preparación del filtro que usa Simeta, así como que declare haberlo aprendido de un asirio (Theoc. Idil. II, 163-164); dándose con ello la dualidad de relacionar la magia con la mujer y con lo extranjero. Se trata de una hechicera no profesional, una mujer que no duda en usar las prácticas hechiceras que ha aprendido para conseguir sus fines (Martin 2012: 124). Las prácticas de Simeta $^{7}$, que se dan siempre bajo la protección de la noche, combinan conjuros, hierbas, drogas, fuego y amuletos mágicos, además de una prenda de Delfis y la libación en la puerta de la casa del joven (Theoc. Idil. II, 18-51).

Como esta, Deyanira, la hechicera que presenta Sófocles en Las Traquinias, se sirve del empleo de plantas y pócimas. Se trata de una mujer normal que cegada por los celos no duda en usar la magia aunque es consciente de que obra mal: en un arrebato de desesperación empapa en una poción ${ }^{8}$ una capa que envía a su marido, quien enferma (Martin 2012: 122- 123).

Aunque la obra de Teócrito procede del siglo III a.C. y la de Sófocles del V a.C., ambas comparten la visión de unas hechiceras más evolucionadas y con mayores capacidades, que las presentadas por autores más antiguos. Denotan una evolución del imaginario popular, que aporta nuevas características a estas mujeres. Se trata pues de dos aspectos de importancia: de una parte se recalca la impulsividad de la mujer y la falta de escrúpulo para recurrir a prácticas mágicas, llevada por el deseo, aun sabiendo de lo inapropiado de estas; nos muestra un elemento de gran implicación social pues se trata de una mujer sin conocimientos mágicos, que no duda en adquirirlos y usarlos sin conocer sus consecuencias, con lo cual la posibilidad del uso de la hechicería se extiende a todas las mujeres que quieran usarla para conseguir sus fines. Reside aquí la gran evolución en la concepción de la magia, que abandona lo salvaje y externo a la ciudad, para convertirse en un peligro real en el imaginario popular.

\footnotetext{
${ }^{7}$ En su práctica invoca a Hécate y Selene, divinidades de la noche, funde una figurilla de cera del joven ${ }^{7}$, añade una planta mágica de Arcadia (la zona de Grecia más relacionada a la brujería) y recita una serie de conjuros claramente intimidatorios "los huesos de Delfis esparzo" que pretenden, mediante la palabra, hacer real lo que recitan. (Theoc. Idil. II, 18-51)

${ }^{8}$ Deyanira había obtenido la poción del centauro Neso, justo mientras este moría a manos de Heracles. Soph. Trach. 680.
} 
La literatura griega nos lega pues, con estos cuatro ejemplos, una imagen completa de la hechicera, que refleja lo peligroso del uso de prácticas tan poderosas en manos de seres tan impulsivos como las mujeres; son un paradigma de la imagen general de la mujer en el mundo griego, o al menos del potencial de las mismas. Fundamentalmente representan el peligro del mundo salvaje, aquel que excede los límites de lo urbano y la protección de las murallas, y lo cívico, convirtiéndose en un peligro real para los ciudadanos (Stratton 2006: 43-44). Circe causa el mal a los hombres sin razón y solo remite su ataque cuando ve calmado su deseo sexual por el héroe. Medea no duda en traicionar a su familia y patria. Simeta no teme condenar a muerte al héroe al que ama. Y Deyanira, a pesar de no ser hechicera no tiene dificultad para adquirir el empleo de estas prácticas. La mujer se muestra pues como una criatura malvada, impulsiva, vengativa y traicionera que, llevada por su deseo sexual es capaz de todo (Stratton 2009: 79). Peor aún, cualquier mujer es potencialmente peligrosa en tanto que puede acceder a la brujería con facilidad. Se trata del mayor peligro para el héroe, ejemplo de ciudadano, que se ve superado por las prácticas mágicas y acaba siendo la víctima.

\subsection{Las hechiceras a ojos de los romanos}

Las hechiceras heredadas de la literatura griega, serán ampliamente utilizadas por los autores romanos, que les otorgan nuevos enfoques y poderes, mostrando a unas mujeres de habilidades muy superiores, que las hacen más terribles que seductoras; evolucionan con nuevos prototipos que derivan en brujas viejas y de características físicas negativas (Stratto 2005: 47). Así, por ejemplo, la historia de Jasón será versionada por Ovidio y Apolodoro, que incidirán en algunas prácticas mágicas de Medea; en la versión de Apolodoro, acabado el viaje, Medea llega junto a Jasón a Yolco, el hogar de este, donde convence con sus artes a las hijas de Pelias ${ }^{9}$ para que despedacen al padre y lo cocinen (A.R. I, 144); en la de Ovidio, Medea $^{10}$ espera a la noche de luna llena, sale con

\footnotetext{
${ }^{9}$ Pelias, tío de Jasón, había usurpado su trono y enviado al héroe a cumplir una misión imposible; Medea convence a las hijas de este para que lo despedacen al prometerles que de esta manera quedaría rejuvenecido.

${ }^{10}$ Medea muestra aquí las características propias de una hechicera, sin embargo es de tener en cuenta que la obra de Ovidio es de época imperial romana tendiendo a la visión de su tiempo.
} 
los pies desnudos (símbolo del contacto con el mundo ctónico), conjura a los astros, a Hécate y los dioses de los bosques y de la noche, recoge hierbas y con ellas, tras aplacar a Hades y Perséfone, prepara una pócima con la que rejuvenece a un anciano (Lillo 2013: 161-163). Se trata pues de una clara reutilización del personaje griego, muestra de la influencia literaria griega en la concepción romana; si bien estos hacen evolucionar al personaje haciéndola más sanguinaria y deshumanizada (Martins 2015: 162).

Destacan otras hechiceras en los autores romanos, que presentan unas características comunes y son muestra del imaginario romano sobre estas poderosas mujeres que, por sus artes, podían escapar del control del sistema patriarcal de la ciudad; reúnen características que según el imaginario colectivo romano son ejemplo de las propias de las mujeres. La hechicera surge así, en nuestra opinión, como reflejo de lo que la sociedad romana consideraba que la mujer era en potencia, lo que la mujer podía ser si escapaba al riguroso control del sistema patriarcal por medio del conocimiento de las artes oscuras que le son propias. De nuevo un irracional impulso motiva sus actos: el desenfrenado deseo sexual que los romanos atribuyen a la mujer pues tienen tendencia natural al adulterio (Sen. Ben 3, 16), y contra lo que los romanos imponen las más severas penas. Así Dido ${ }^{11}$, que en la obra de Virgilio queda perdidamente enamorada de Eneas, loca de amor por él, acaba suicidándose cuando finalmente este la deja, tras sus fracasados intentos de mantenerlo a su lado mediante prácticas mágicas (Mérida 2004: 51). Del mismo modo, la hechicera Canidia ${ }^{12}$, que desea que su amante Varo vuelva a su lecho tras haberla dejado encantado por otra hechicera, usará las más oscuras artes para conseguirlo y un poderoso filtro de amor al que no podrá resistir (Hor. Epod. V, 70-75). Así ocurre también con una de las hechiceras de La Metamorfosis de Apuleyo, Pánfila,

\footnotetext{
${ }^{11}$ Dido, la mítica reina de Cartago se remonta a la antigüedad mitológica; será sin embargo en la Eneida de Virgilio donde aparezca la imagen que tenemos de la misma. Destaca la sagacidad de esta, quien tras su huida de Tiro, para fundar la ciudad de Cartago pide en el norte de África a los indígenas la cantidad de tierra que ocupara una piel de toro; haciendo tiras una piel de este animal y uniendo estas, creó un gran perímetro donde levantaría la ciudad de Cartago.

${ }^{12}$ Canidia aparece en diversas partes de la obra de Horacio, en ocasiones en compañía de otras hechiceras. Horacio muestra con profundidad las diversas prácticas mágicas existentes en su tiempo, que llevan a la prohibición de las mismas; muestra ello de la amplia creencia en la época. Su obra, influenciada por la política de su época parece querer mostrar una visión ridiculizada de estas mujeres en un intento de modificar el imaginario colectivo para evitar el temor a las mismas.
} 
que usa de sus artes tanto para atraer a su lecho a jóvenes (Apul. Met. III, 16, 1-2), como para ir a su encuentro trasformada en ave (Apul. Met. III, 21, 5-6).

Destaca también la faceta de alcahueta: si no usan la magia para atraer a jóvenes, usan de sus conocimientos para ayudar a otras mujeres en el mismo fin. Este es el caso de Acántide ${ }^{13}$, una vieja hechicera alcahueta que pretende convencer a Cintia de que abandone a su amado (Lillo 2013: 171). Dipsas ${ }^{14}$, otra famosa hechicera alcahueta que presenta Ovidio en el Libro de los Amores actúa como consejera pervertidora de una joven a la que muestra cómo manejar a los hombres (Mérida 2004: 68). Petronio muestra a la hechicera alcahueta Proseleno en El Satiricón, quien por petición de la joven Crisis, ayudará a esta a conseguir que su amado Encolpio recupere la potencia sexual mediante un encantamiento (Petr. XXIX- XXI). Las hechiceras suelen pues actuar como alcahuetas mediante el uso de la palabra pervirtiendo a las jóvenes, pero también mediante brebajes y conjuros en relación con el aspecto sexual. Además suelen ser meretrices o lenas, así Canidia y sus compañeras son prostitutas, como se deduce del estudio de sus nombres según Martin (2012: 135).

Se la asocia también al consumo desmedido de alcohol ${ }^{15}$, siendo tachadas de borrachas, como ocurre con Acántide (Prop. IV, 5, 46) o Dipsias, que son presentadas como "sedientas" y "entregadas a la bebida" (Ogden 2009: 127-129). Otros autores muestran una imagen más cercana a lo irreal con hechiceras de aspecto maligno y físico repugnante, reflejo de su interior horrendo y malvado. Es el caso de Canidia (Hor. Epod. $\mathrm{V}, 15)$ presentada como una hechicera vieja que porta víboras entre sus cabellos; y que en la Sátira I (Hor. S. I, 8) se presenta junto a Sagana como extremadamente pálidas y dando feroces alaridos (Martin 2012: 136). El culmen de la hechicera siniestra podemos encontrarlo en la obra de Lucanno, que presenta a Ericto como una hechicera que abomina

\footnotetext{
${ }^{13}$ Acántide es mostrada por Propercio (IV, 5) en su obra Elegías. Debido al realismo de su descripción y al odio que parece profesarle el propio poeta, protagonista de la obra, parece esconder la figura de una hechicera real.

${ }^{14}$ Dipsas, ha sido considerade por algunos autores como un personaje que pudiera estar encubriendo a una alcahueta real.

${ }^{15}$ Dionisio de Halicarnaso (II, 25) nos habla de las peores faltas atribuibles a una mujer según las leyes de Romulo; entre estas destaca al adulterio y al consumo de vino, que lleva, debido a la ligereza propia de las mujeres a la primera de las faltas.
} 
de las casas y prefiere vivir en tumbas abandonadas; tiene cabellos desgreñados, un rostro escuálido y repugnante, y un aliento pútrido y mortífero (Lucan. VI., 507-520).

Siguen rodeándose de criaturas salvajes. Canidia y Sagana aparecen rodeadas de perros y de serpientes (Hor. S. I, 8), Ericto se acompaña de ladridos de perros, gemidos de lobos, ulular de búhos y silbar de serpientes (Lucan. VI., 507-520; Martin 2012: 139). Resulta llamativa la coincidente reflexión sobre la relación de estas con los perros, sin duda referencia a Hécate. Esta relación con el mundo de lo salvaje se refleja en una de sus capacidades más comunes, la transformación en otras criaturas mediante el uso de conjuros, brebajes y ungüentos. Posiblemente la más conocida muestra de esta práctica sea la que describe Apuleyo en La Metamorfosis, donde Pánfila tras untarse todo el cuerpo con un ungüento se transforma en búho (Apul. Met. III, 16, 1-2 y 25, 1; Ogden 2009: 141145). Como ésta, Dipsias es capaz de transformase en ave, lo que permite que revolotee por las noches (Mérida 2004: 65). La metamorfosis en pájaros es posiblemente la más común, destacando el búho, quizá por ser ave nocturna y ciertamente astuta. La misma práctica transformadora en animales aparece en otras hechiceras, así Acántide podía cambiar su forma según su antojo y tenía por costumbre pasear por los cementerios de Roma convertida en una especie de mujer-loba (Mérida 2004: 61).

La hechicera es un ser peligroso, que puede atacar la integridad de cualquier individuo, mujer u hombre, sin tener más razón que su propia maldad: no dudan en provocar mal a los amantes sin esperanza de obtener nada a cambio, como hacen las hechiceras alcahuetas de Ovidio; tampoco en provocar un tormento tal que lleve al suicidio a quien tenga la poca fortuna de caer en mala gracia a la hechicera, como sucede con las de Horacio; ni en matar a quien sea necesario para elaborar sus conjuros, como ocurre con el joven al que matan ritualmente Canidia y sus compañeras (Ogden 2009: 117-118). Tal es su maldad que no dudaran, para resarcir su ánimo de venganza, ni en matar a su propios hijos ni a sí misma, como hace Dido al suicidarse embarazada (Mérida 2004: 52).

Si por algo destacan las hechiceras, es por su amplio conocimiento de las plantas y las pócimas, que podríamos relacionar a la supuesta ancestral división de trabajos que 
convertía a las mujeres en recolectoras de plantas y, por tanto, conocedoras de éstas y sus posibilidades, con su vinculación con el cuidado de los enfermos y las hierbas curativas o con el cocinado de los alimentos. Si bien hay que tener en cuenta que no todas las pócimas habían de ser ingeridas, pues muchas se aplicaban como ungüento o tenían validez por el hecho mismo de su elaboración y uso ritual. Todas las hechiceras hacen uso de las hierbas en la elaboración de sus pócimas, si bien intervienen otros elementos en sus conjuros: desde el uso de animales al de minerales ${ }^{16}$. En ocasiones basta con manipular las hierbas, así Simeta no tiene más que quemarlas para que tenga efecto su conjuro (Mérida 2004: 49); en otras es necesario que la víctima las tome como en el caso del soldado muerto al que Ericto sazona (Lucan. III., 710); destacan las aplicaciones como ungüento, como ocurre con la metamorfosis de Pánfila (Apul. Met. III, 16, 1-2) o la protección de Jasón por el ungüento de Medea (A.R. III, 845- 857).

Otro de los aspectos más temibles de la hechicera es el conocimiento del oscuro arte de la nigromancia, capacidad con la que actúa más allá del umbral de la muerte; así el mal que puede causar la hechicera sobrepasa el mundo de los vivos. Los muertos adquieren uso por parte de la hechicera en dos formas: el uso de los cuerpos de los difuntos para la elaboración de sus pócimas y la práctica nigromántica con la interrogación de los difuntos. El primero de los casos podemos ejemplificarlo con el relato de Telifrón (Apul. Met. II, 21, 7) al que encargan vigilar un cadáver porque las hechiceras solían desgarrar los rostros de los difuntos para hacerse con ingredientes para sus pócimas, o en la escena que narra Trimalción en El Satiricón de Petronio sobre el robo del cadáver de un niño por parte de unas hechiceras (Petr. XXIX- XXI). El segundo caso aparece desde Circe que indica a Ulises como contactar con Tiresias, hasta Ericto que resucita a un soldado muerto en batalla para interrogarle (Mérida 2004: 71). Resulta de especial interés para éstas aquellos difuntos que han permanecido insepultos o muertos en situaciones traumáticas, por su dificultad para alcanzar el mundo de los muertos y cuyas almas quedan vagando a disposición de la hechicera, que puede hacer uso de ellas mediante sus prácticas, en particular cuando son niños (Martin 2013: 41-44).

\footnotetext{
${ }^{16}$ Sobre los diversos elementos usados por las hechiceras en las elaboraciones mágicas véase Martin, 2012: 45-54.
} 
Junto al uso de las pociones cabe destacar de nuevo la importancia de la palabra conjurada de vital importancia para completar los ritos. El control de la palabra tanto en la realización de conjuros como para convencer; la hechicera es por tanto peligrosa para la seguridad de la ciudad tanto por sus capacidades mágicas como por su tendencia alcahueta. Tienen además otra serie de poderes maravillosos destacando una cualidad propia de muchas de estas hechiceras que las relaciona más aun con la noche: su capacidad para hacer descender la luna. Esta creencia la muestran desde Aristófanes (Un., 749 - 752) a Tibulo (I, 2, 43-52), que nos habla de una hechicera capaz de hacer descender la luna, o la propia Medea de Apolonio (A.R. III, 534).

A pesar de todo, el verdadero temor a la hechicera no se encuentra tanto en las grandes capacidades de estas, que en ocasiones se igualan a las de los dioses, como en el hecho mundano de que cualquier mujer puede participar de estas prácticas, no quedando reducidas a las hechiceras. Las mujeres pueden aprender a realizar las prácticas mágicas por sí mismas, como en el caso de Dido, que obtiene los conocimientos mágicos de una hechicera del pueblo de los Massyles (Martin 2013: 125). El peligro potencial de las hechiceras reside pues en que estas pueden enseñar sus prácticas a otras mujeres suponiendo un peligro para el sistema patriarcal que puede verse afectado si no se las controla de forma adecuada. Las hechiceras son pues poderosas y peligrosas y tienen tendencia a unirse en una suerte de aquelarres que aumentan la peligrosidad que ya poseen como ocurre con Canidia.

\section{La realidad de las hechiceras}

La magia se presenta desde dos perspectivas: la concepción ideológica de la misma, que hemos visto y la práctica real de esta. Se trata de dos mundos paralelos que se retroalimentan y configuran mutuamente de modo que encontramos elementos comunes a ambos, como los componentes naturales usados o las diversas prácticas; sin embargo, de la misma forma encontramos elementos que describe la literatura y cuya práctica parece del todo imposible. La concepción de las hechiceras por la literatura excede las actividades que pudieron ser ejecutadas por las hechiceras reales, pero sin 
embargo, estas existieron como practicantes reales de magia como muestran infinidad de restos materiales, simbología y prácticas que sobreviven hasta nuestros días. (Luck 2006: 46-51)

\subsection{Restos de la práctica mágica}

La existencia de la magia y su uso estaba verdaderamente extendido en la antigüedad; siendo los restos de las prácticas mágicas numerosos. Destacan las tablillas de maleficios y los papiros mágicos, por su carácter de fuente escrita, que permiten un conocimiento preciso de las formas rituales y de las fórmulas utilizadas. La plasmación de los hechizos por escrito destaca como forma de asegurar su pervivencia en el tiempo. Los papiros mágicos fueron auténticos compendios mágicos donde recogieron fórmulas y hechizos que pretendían controlar los elementos del entorno del conjurante. Junto a estos aparecen los protocolos necesarios para ejecutar los conjuros y las fórmulas para elaborar pociones y fabricar amuletos; así como las prácticas manticas.

Por otro lado, las tablas de maldiciones o tabellae defixionum ${ }^{17}$ revelan que la magia fue una práctica popular que por la sencillez de su ejecución no requería de personal experto; si bien la existencia de fórmulas mágicas de cierta complejidad, las mismas que se mencionan también en los papiros mágicos, plantea la necesidad de que existieran individuos "profesionales" con acceso a estos, a los que acudiera la población (Teja 2014: 51-52). La convicción de la hechicera en particular o su intento de obtener beneficio con estas prácticas se desconoce, así como la intervención de la hechicera en el proceso de deposición de estas.

\footnotetext{
17 Tablillas normalmente elaboradas en plomo aunque también en oro o plata, en las que se escribían fórmulas mágicas; solían ser enrolladas y depositas en determinados lugares, relacionados con el mundo ctónico, como pozos.
} 


\subsection{La práctica real de la hechicería}

En las tablas de defixio, aparecen individuos no profesionales y hechiceros, hombres y mujeres. Si bien la idea literaria las señala a ellas como principales ejecutoras, hemos de tener en cuenta que la literatura estaba en manos de los hombres, pues de hecho, las mujeres aparecen en menor medida que los hombres en estas tablillas (Teja 2014: 6162). Al principio las prácticas mágicas parecen estar relacionadas con individuos excluidos de otras formas religiosas y de participación en la comunidad, los no ciudadanos; aunque en el Imperio romano, la práctica se expande por las diferentes capas sociales, llegando a ser realizadas incluso por los emperadores (Flint y otros 1999: 5471).

Desde la antigüedad, el interés por estas prácticas hizo que diversos autores las estudiasen. Plinio ( $H N, \mathrm{XXX}, 1-2)$ considera que la magia reúne las tres grandes artes que tienen poder sobre el espíritu humano: la medicina, la religión y la astrología. La magia médica resulta de gran interés como forma de curación más allá de la practicable; se centraban en la curación de diversos males, sobre todo las fiebres, de difícil explicación, y enfermedades de carácter psicológico para las que no encontraban respuesta. Por otro lado, servían para protegerse de males diversos, mediante amuletos o mediante fórmulas mágicas, en particular el uso para protegerse de otras artes mágicas negativas, especialmente a bebés y hogares, protegidos amuletos o formulas diversas. Otro uso protector era el de los maleficios que protegían, por ejemplo, las tumbas y a los muertos contra posibles profanaciones; y junto a este el fenómeno de la devotio, por el que se pactaba con fuerzas divinas su intervención favorable contra un enemigo.

Son comunes los maleficios para eliminar a un individuo, cuya ritualización aparece en los papiros mágicos, que describen como han de realizarse las tablillas. Destaca también la práctica para atraer a una persona con fines eróticos mediante los agogai $^{18}$ y los philtrokatadesmoi ${ }^{19}$; junto a estos cabe añadir la confección de figurillas, descritas en los papiros, a las que aplicados ciertos rituales procuraban que la víctima del

\footnotetext{
${ }^{18}$ Oraciones destinadas a atraer a una persona hasta la casa y la cama.

${ }^{19}$ Conjuros que pretenden hacer dependiente del conjurador a la víctima de este.
} 
hechizo no tuviese placer más que con la hechicera y figurillas que representan a individuos y eran mutiladas (Martin 2012: 70-85).

Finalmente cabe mencionar entre las prácticas mágicas cotidianas la adivinación otro arte mágico por excelencia en varias formas. La ejecución de esta podía realizarse de formas diversas. Encontramos así adivinación directa mediante la revelación divina durante la posesión o mediante sueños; con el empleo de objetos o animales que muestran símbolos interpretables; o mediante el uso de la necromancia, el arte de consultar a los muertos ofreciéndoles libaciones que los hacían volver a la vida (Luck 2006: 287-311). La adivinación como práctica mágica resulta particularmente controvertida en tanto que en ocasiones es una práctica aceptada por la comunidad, no hay más que recordar, por ejemplo, al Oráculo de Delfos o los augurios romanos; mientras en otras, resulta una práctica que extralimita los confines de esta, como ocurre, por ejemplo, con las prácticas nigrománticas.

\section{Conclusión}

La existencia de las prácticas mágicas queda atestiguada por diversas fuentes en la antigüedad; y más aún en la literatura. Las hechiceras de la literatura no solo reflejaron a las verdaderas hechiceras que practicaban la magia, sino que crearon unos prototipos de calaron en el imaginario popular y que, en cierto modo, influyeron en el imaginario sobre las practicantes. La fuente primera de este imaginario fue sin duda Grecia, en cuya literatura ya encontramos muchos de los elementos que serán propios de las hechiceras; si bien serán los romanos quienes las hagan evolucionar y lleven al extremo el ideario sobre las mismas.

En buena medida, las hechiceras no fueron más que mujeres sabias que tuvieron un conocimiento de la naturaleza, que utilizaban para sanar. Sin embargo, algunas otras formas de magia popular fueron oscuras y perniciosas: muchas de estas tendrían un origen real y algunas otras posiblemente surgieron a partir del conocimiento de las prácticas de las hechiceras de la literatura. Otras muchas formas de brujería son sin duda invenciones, 
más teóricas que reales. En cualquier caso, la imagen de las mismas, reflejada en la literatura, se hizo más compleja y negativa con el avance de la historia desde la Grecia clásica hacia el Imperio romano.

En otros casos las hechiceras directamente no existieron, no fueron más que vanas formas de justificación de los males que atacaban a la ciudad. En estas ocasiones las mujeres fueron acusadas de hechicería perniciosa, como se ha hecho a lo largo de la historia y condenadas creyendo que eran la fuente del mal que les acechaba. Del mismo modo, la ciudad utilizaría el temor a estas para usos propios de control social, como también se haría a lo largo de la historia. En cualquier caso, la mujer siempre fue relacionada con las formas de magia negativa, mientras se reservaban espacios para la una "magia beneficiosa" en los que solo tenía cabida el hombre.

Donde no cabe duda de la existencia de hechiceras es en la literatura en que aparecen. Algunas fueron posiblemente el reflejo de una realidad poco conocida por los autores, quienes no tuvieron reparo en modificar su visión para crear mujeres de capacidades sobrenaturales y pensamientos perversos. El imaginario literario en manos de los hombres dio vida a estas mujeres, cuyas figuras y poderes, del todo imposibles a nuestros ojos, eran perfectamente viables a los de las gentes de la antigüedad, en cuyo imaginario calaron.

Finalmente, incluso las deidades patronímicas de estas prácticas que excedían los límites de lo correcto, fueron femeninas, señalándose como fuente primaria de la magia a la diosa Hécate. Si bien es cierto que también forma parte de este grupo algún dios de forma aislada, normalmente lo hace como contrapunto a la magia perniciosa o fuente de magia positiva o, en su defecto, en relación con esta diosa u otras relacionadas con este campo.

Tanto unas como otras no fueron sino resultado del moldeo de los hombres de su tiempo en el intento de uso de estas como forma de acusación al género femenino, en la pretensión de dominio de estas, que se veía amparado en la necesidad de control del gran peligro que la magia suponía para la supervivencia de la comunidad. 


\section{Fuentes clásicas}

Apolodoro de Atenas. 2001. Biblioteca. Español. Madrid: Gredos (introducción J. Arce, traducción y notas M. Rodríguez de Sepúlveda).

Apolonio de Rodas. 2004. Argonáuticas, Español. Madrid: Alianza (traducción e introducción de C. García Gual)

Apuleyo. 2003. Metamorphoses. Bilingüe español- latín. Madrid: CSIC (introducción, traducción y notas de J. Martos).

Aristofanes. 1984. Apología de Sócrates. Español. Barcelona: Orbis.

Dionisio de Halicarnaso. 1984. Historia Antigua de Roma. Español. Madrid: Gredos (Introducción de D. Plácido, traducción y notas de E. Jiménez y E. Sánchez).

Euripides. 2015. Medea. Español. Barcelona: Penguin Clásicos (introducción y traducción de R. Irigoyen y epílogo de J. Balló y X. Pérez).

Hesiodo. 2011. Teogonía, Trabajos y días. Español. Madrid: Alianza (presentación de Tariq Ali, traducción de A. Martín Sánchez y M. Martin Sánchez).

Homero. 2007. Odisea. Español. Madrid: RBA (traducción de J. M. Pabón y prólogo de C. García Gual).

. 2001. Himnos homéricos. Démeter. Bilingüe español-griego. Pamplona: Ediciones de la Universidad de Navarra (introducción, edición traducción y comentario de J. Torres Guerra).

Horacio Flaco. 2011. Epodon liber. Español. Madrid: Gredos (presentación y traducción de J. L. Moralejo). Lozano).

Lucano. 2011. Farsalia. Madrid: Gredos (introducción y traducción de A. Holgado Redondo).

Petronio Arbitro. 2006. Satiricón. Español. Madrid: Cátedra (traducción de B. Segura Ramos).

Plinio Segundo. 2002. Naturalis historia. Español. Madrid: Cátedra (traducido y anotado por J. Cantó et al.).

Propercio. 2001. Elegiae. Español- latín. Madrid: Cátedra (introducción de F. Moya Y C. Puche, traducción y notas de F. Moya y A. Ruiz de Elvira).

Seneca. 1986. Consolación a mi madre Helvia; Cartas a Lucilio; Sobre los Beneficios. Barcelona: Salvat (introducción, traducción y notas de J. C. García-Borrón). 
Sofocles. 1995. Las Traquinias. Español. Madrid: Ediciones Clásicas (versión de M. Benavente).

Teocrito. 1986. Bucólicos griegos. Español. Madrid: Gredos (introducción y traducción de M. García Teijeiro y M. T. Molinos Tejada).

Tibulo. 2011. Elegiae. Español. Madrid: Gredos (introducción y traducción de A. Soler).

\section{Referencias bibliográficas}

Apud, Ismael. 2011. "Magia, ciencia y religión en antropología social. De Taylor a LeviStrauss", Nómadas. Revista de Ciencias Sociales y Juridicas, no 30, 2: 337-353.

Dickie, Matthew W. 2005. Magic and magicians in the Greco-roman world. London: Routledge, Taylor and Francis Group.

Esteban Santos, Alicia. 2005. "Mujeres terribles (Heroínas de la mitología griega I)", $\mathrm{CFC}(\mathrm{G})$ : Estudios griegos e indoeuropeos, $\mathrm{n}^{\circ}$ 15: 63-93

Fernández Delgado, José Antonio. 2006. "Diosas y/o brujas, hechiceras míticas (y menos míticas) de Grecia”, MHNH: Revista internacional de investigación sobre magia y astrología antiguas, $\mathrm{n}^{\circ}$ 6: 93-108.

Flint, Valerie, Gordon, Richard, Georg Luck y Daniel Ogden. 1999. The Athlone of Witchcraft and Magic in Europe, vol 2, Ancient Greece and Rome. London: Athlone Press.

Galindo Esparza, Aurora. 2013. El tema de Circe en la tradición literaria: de la épica griega a la literatura española. Tesis Universidad de Murcia, Facultad de Letras.

Lillo Redonet, Fernando. 2013. Fantasmas, hechiceras y magos de Grecia y Roma. Madrid: Ediciones Evohé.

Luck, Georg. 2006. Arcana Mundi. Magic and the Occult in the Greek and Roman Worlds. A collection of Ancient Texts. Baltimore: The Johns Hopkins university press.

Martin, Michaël. 2005. Magie et magiciens dans le monde gréco-romain. Paris: Errance. 2012. La magie dans l'Antiquité. Paris: Ellipses.

Martins de Jesus, Carlos. 2015. “Madre o monstruo? Medea en la Antología Griega”, Myrtia, $\mathrm{n}^{\circ}$ 30: 145-166.

Mérida Jiménez, Rafale. 2004. El gran libro de las hechiceras. Barcelona: RBA.

Muro Meléndez-Valdés, Pilar. 2000. "Sobre las hechiceras romanas". El dios que hechiza y encanta. Magia y Astrología en el Mundo Clásico y Helenístico. Coord. Jesús Peláez del Rosal. Córdoba: El almendro. 233-243. 
Ogden, Daniel. 2009. Magic, Witchcraft, and Ghosts in the Greek and Roman Worlds. Oxford: Oxford University Press.

Stratton, Kimberly. 2007. Naming the witch: magic, ideology and stereotype in the ancient world. New York: Columbia University Press.

Teja Reglero, Natalia. 2014. "Mujer y magia en el mundo romano occidental: la imagen femenina en las tabellae defixionum eróticas", Revista Historia Autónoma, nº 4:4762.

Vázquez, Hoys, Ana María. 1989. “Aproximación a la magia, la brujería y la superstición en la antigüedad”, Espacio, Tiempo y Forma, Serie II, Hf Antigua, nº 2: 171-196.

Villalba Babiloni, Teresa Encarnación. 2015. "Hécate, una diosa de los caminos". III Congreso Virtual sobre Historia de las Vías de Comunicación, del 15 al 30 de septiembre de 2015. Coords. Enrique Escobedo Molinos, Juan Antonio López Cordero y Manuel Cabrera Espinosa. 1-11. 